\title{
Chilling of Endodormant Peach Propagules: III. Budbreak and Subsequent Growth of Physiologically Dwarfed to Near Normal Seedlings
}

\author{
James W. Frisby ${ }^{1}$ and Schuyler D. Seeley ${ }^{2}$ \\ Plants, Soils, and Biometeorology Department, Utah State University, Logan, UT 84322-4820
}

\begin{abstract}
Additional index words. Prunus persica, temperature responses, forcing, chilling requirement, dormancy
Abstract. We studied the response of physiologically dwarfed (PD) to near normal peach [Prunus persica (L.) Batsch] seedlings ('Johnson Elberta' seeds) to various chilling treatments. Peach seedlings were obtained by forcing seeds that had been subjected to a brief stratification treatment. Seedlings were divided into four types (groups) according to the length of the primary stem and the presence and size of lateral branches. The seedlings were used in a chilling study with treatments of five durations (20 to 60 days) at four temperatures $(2$ to $14 \mathrm{C})$. Terminal shoot growth and lateral budbreak were recorded 17 days after forcing. Shoot and leaf dry weight were obtained after seedlings had grown for 64 days. Budbreak and growth improved with the duration of the chilling treatment. Generally, 7C was the best chilling temperature, with 2 or $10 \mathrm{C}$ only slightly less effective. Treatment at $14 \mathrm{C}$ did not promote budbreak or growth. Budbreak and growth had significant interactions between treatment duration and temperature. The seedling type and treatment duration interaction was significant for terminal shoot length, lateral budbreak, and leaf dry weight, but were probably the result of differences between the seedling types before treatment and not true interactions with the length of the treatment. There was a significant interaction between the seedling type and treatment temperature on terminal shoot growth. Subsequent shoot growth did not differ significantly between the seedling types after similar chilling treatments. Thus, shoot growth was the best indicator of the chilling process of 'Johnson Elberta' peach seedlings. Indicators of dormancy removal such as lateral budbreak or terminal shoot growth after 17 days forcing were not good predictors of subsequent seedling growth.
\end{abstract}

Seeds and excised peach embryos forced to germinate without adequate chilling develop into abnormal seedlings called physiological dwarfs (Chao and Walker, 1966; Flemion, 1934; Zigas and Coombe, 1977). The highly variable growth of PD peach seedlings (Flemion, 1959; Flemion and Beardow, 1963; Tukey and Carlson, 1945) can be modified to appear normal by applying gibberellic acid or by exposure to long photoperiod (Flemion, 1959). These treatments modify growth only temporarily and do not overcome the abnormal leaf development problem. PD peach seedlings chilled at 5 to $7 \mathrm{C}$ for 35 to 63 days grow and develop normally (Davidson, 1934; Flemion, 1959).

Does chilling have the same effects on PD seedlings as on seeds, buds from mature trees, or buds of normal seedlings? We tested the ability of endodormant peach seedlings, ranging from severely PD to near normal, to break endodormancy after minimal to optimal chilling treatments. This study also provided data for comparison with the chilling responses of peach seedlings, seeds, and buds of mature cuttings (Frisby and Seeley, 1993c).

\section{Materials and Methods}

PD peach seedlings were obtained by a brief seed stratification treatment. Seeds were obtained from 'Johnson Elberta' peaches havested from the Utah State Univ. Experimental Station, Kaysville, in Aug. and Sept. 1986. Pits were removed, air dried, and cracked open to remove the seed. Most of the seeds used in this experiment had cracks or nicks in the seedcoat, which should have

Received for publication 4 Feb. 1992. Accepted for publication 1 Sept. 1992. This report is based, in part, on research conducted and supported as part of SAES Western Regional Research Project W-130. Utah Agr. Expt. Sta. J. Paper no. 4270. The use of trade names does not imply endorsement of the products used nor criticism of similar ones not mentioned. The cost of publishing this paper was defrayed in part by the payment of page charges. Under postal regulations, this paper therefore must be hereby marked advertisement solely to indicate this fact. 'Graduate Research Assistant.

${ }^{2}$ Professor. enhanced the ability to germinate after a brief stratification treatment (Chao and Walker, 1966). Seeds were placed into plastic bags with peatmoss moistened with a suspension of $N$-trichloromethylthio-4 cyclohexene 1,2 dicarboximide (Captan) at $0.15 \%$ a.i. (w/v) (50 WP, Stauffer Chemical, Westport, Conn.). Temperature control was provided in chambers described previously (Frisby and Seeley, 1993a). Seeds were stratified for 23 days at 4C, then moved to $20 \mathrm{C}$. No seeds germinated within 10 days, so they were placed at $4 \mathrm{C}$ for 10 additional days and again forced at 20C. Germinated seeds were planted in plastic pots $(470 \mathrm{~cm}$ ') containing commercial potting mix (Metro-Mix 300, W.R. Grace \& Co., Fogelsville, Pa.). Seedlings remained in the greenhouse from winter until Fall 1987 (283 days). At this time, the seedlings appeared endodormant; growth had stopped, leaves were senescent, and most had abscised. Pesticides to control insects and mites were the same as those described previously for other peach seedlings (Frisby and Seeley, 1993b).

During seedling growth it became obvious that variable sizes and growth forms existed. After growth ceased, the primary and lateral stems were measured. Seedlings were grouped into four seedling types (Fig. 1): Type 1: Seedlings with very short primary stems $\{35.7 \pm 2.9 \mathrm{~mm}[ \pm 95 \%$ confidence interval $(\mathrm{CI})]\}$ and short lateral branches [total stem length $(\mathrm{TSL})=39.1 \pm 3.7 \mathrm{~mm}]$. These seedlings were true physiological dwarfs. Type 2: Seedlings with medium length primary stems $(84.8 \pm 3.4 \mathrm{~mm})$ and no lateral branches. These seedlings were semi-physiological dwarfs. This type was the most common. Type 3: Seedlings with short primary stems $(40.8 \pm 2.7 \mathrm{~mm})$ and long lateral branches $(\mathrm{TSL}=188.2 \pm$ $17.5 \mathrm{~mm}$ ). These seedlings had short primary stems, probably due to severe abnormal leaf problems, which may have caused the shoot apexes to abort (Frisby and Seeley, 1993b; Wang and Beardow, 1968). Type 4: Seedlings with long primary stems $(156.3 \pm 4.2 \mathrm{~mm})$ and no lateral branches. These seedlings demon-

Abbreviations: CI, confidence interval; PD, physiologically dwarfed; TSL, total stem length. 


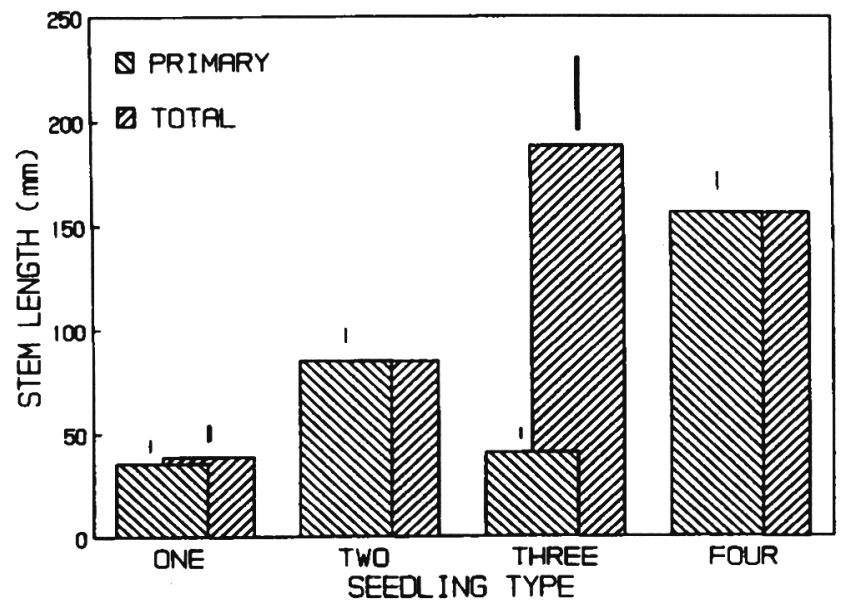

Fig. 1. Size of the four 'Johnson Elberta' seedling types used in the experiment (Lines $=95 \% \mathrm{CI}$ ). Seedling types were separated according to size of the primary stem and presence and size of lateral stems. Type 1 was the smallest and had short laterals, type 2 was intermediate with no laterals, type 3 was intermediate with large laterals, and type 4 was large with no laterals but smaller than seedlings from completely stratified seeds.

strated normal growth and development, but probably were smaller than seedlings from seeds stratified for longer durations.

A split-plot experimental design was used with factorial treatment combinations. The main plot included four seedling types. The subplot included the five durations $(20,30,40,50$, and 60 days), four temperatures (2, 7, 10, and 14C) of chilling, and interactions. Three single-seedling replications were used per treatment.

Growth chambers were used to provide the temperature treat- ments [models CEL 37-14 (Sherer, Marshall, Minn.), PT-80, PGW-132, MB-60B (Percival, Boone, Iowa) for 2, 7, 10, and 14C, respectively]. Seedlings were kept in darkness during treatment. Mean temperatures recorded during the experiment were $2.4 \pm 0.3$, $7.1 \pm 0.3,9.8 \pm 0.1$, and $14.1 \pm 0.04 \mathrm{C}$ ( $\pm 95 \% \mathrm{CI}$, chart recorders $)$.

All seedlings were removed from treatments simultaneously. Seedlings were arranged randomly in a greenhouse set at 24/21C (day/night). The natural photoperiod (from 24 Nov. 1987 to 27 Jan. 1988) was extended to $14 \mathrm{~h}$ by use of $1000 \mathrm{~W}$ high pressure sodium lamps. Each seedling was fertilized with $5.1 \pm 0.2 \mathrm{~g}( \pm 95 \% \mathrm{CI})$ of a slow release fertilizer $(10 \mathrm{~N}-8.8 \mathrm{P}-5.7 \mathrm{~K}$, Osmocote, Sierra Chemical, Milpitas, Calif.).

Terminal shoot growth (length from the bud scales to the tip of longest leaf) was recorded after 17 days of forcing in the greenhouse. When the terminal shoot was dead, the longest lateral terminal shoot was used for analysis purposes. This situation was common with the third seedling type. Lateral budbreak (apparent leaf growth) was recorded 17 days after chilling as number per centimeter stem length.

Seedlings were harvested after they had grown for 64 days. Each seedling was cut at the soillevel, enclosed in a plastic bag, and placed in a cold chamber ( 0 to $2 \mathrm{C}$ ) until measured. Measurements of original growth included length and dry weight of the original, primary, and lateral stems (to calculate lateral budbreak per centimeter). Measurements of new growth included total shoot (21.5 $\mathrm{cm}$ ) and leaf dry weights (dried at 60C).

A split-plot design was used to analyze the data (Table 1). Treatment durations producing no response were excluded from the analysis of variance (ANOVA) calculations. Correlations were used to demonstrate similar responses between the measurements after chilling. Zero values were not used in calculating the correlation coefficients.
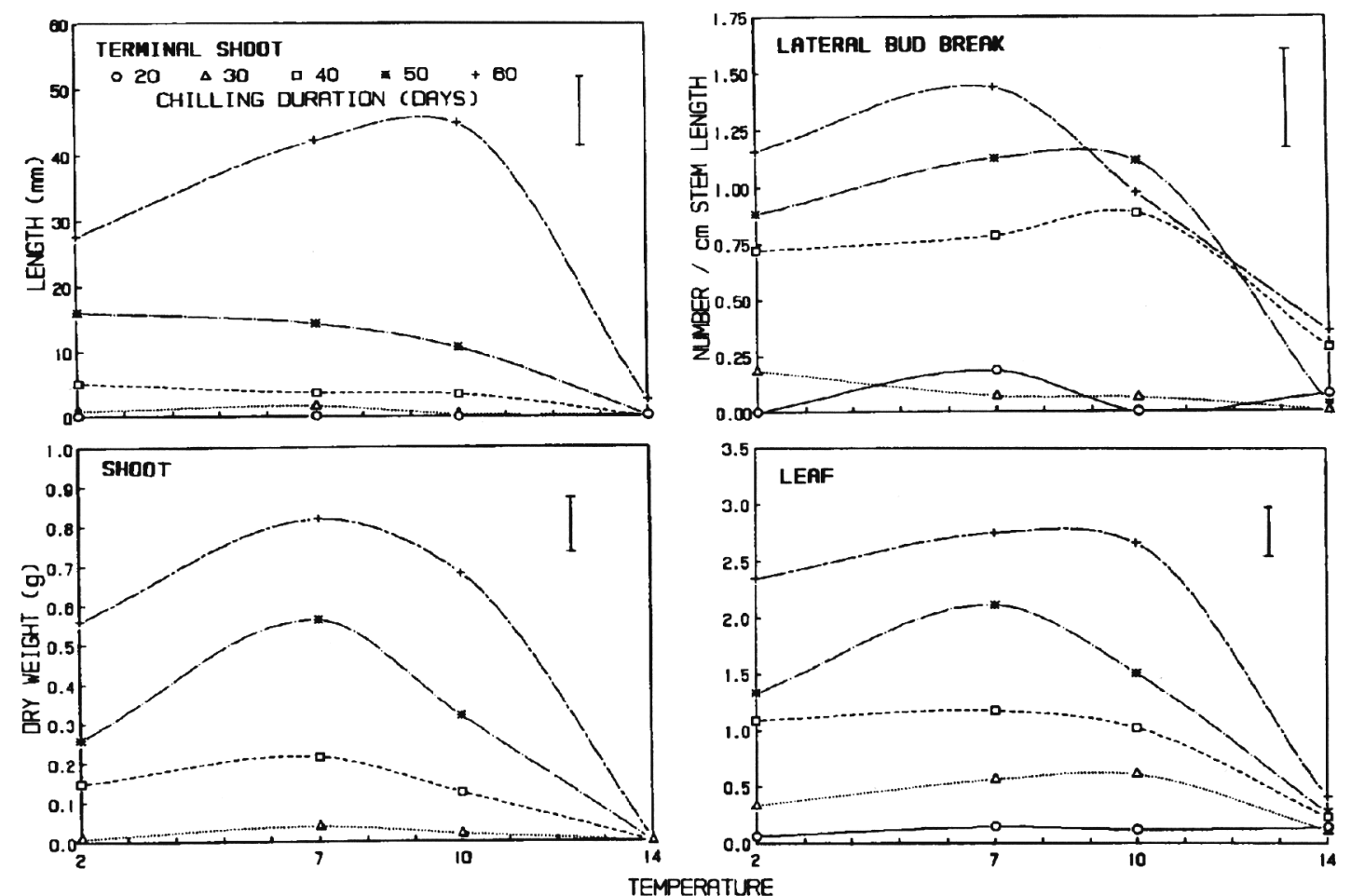

Fig. 2. Interaction between temperature and treatment duration for terminal shoot length and lateral budbreak after 17 days of forcing and shoot and leaf dry weight after 64 days of growth of peach seedlings ('Johnson Elberta' seeds). Values were averaged over the four seedling types. The bars equal the LSD 0.05 for differences among duration and temperature combinations. Trend analysis is provided in Table 1. 
Table 1. Split-plot ANOVA tables for terminal shoot growth, lateral budbreak, shoot dry weight, and leaf dry weight after chilling of seedlings ('Johnson Elberta'). The general design included four seedling types (from severely dwarfed to near normal), five durations (20, 30, 40, 50, and 60 days), and four temperatures $(2,7,10$, and 14C). Durations that led to no growth or budbreak were not included in the ANOVA calculations. Trend analysis is also provided for the main effects and significant interactions.

\begin{tabular}{|c|c|c|c|c|c|c|c|c|}
\hline \multirow{3}{*}{$\begin{array}{l}\text { Sources of } \\
\text { variation }\end{array}$} & \multicolumn{4}{|c|}{ Measured after 17 days } & \multicolumn{4}{|c|}{ Measured after 64 days } \\
\hline & \multicolumn{2}{|c|}{$\begin{array}{c}\text { Terminal shoot } \\
\text { length } \\
(\mathrm{mm})\end{array}$} & \multicolumn{2}{|c|}{$\begin{array}{c}\text { Lateral } \\
\text { budbreak } \\
\text { (number/cm) }\end{array}$} & \multicolumn{2}{|c|}{$\begin{array}{l}\text { Shoot } \\
\text { dry wt } \\
\text { (g) }\end{array}$} & \multicolumn{2}{|c|}{$\begin{array}{l}\text { Leaf } \\
\text { dry wt } \\
\text { (g) }\end{array}$} \\
\hline & $\mathrm{df}$ & MS & df & MS & $\mathrm{df}$ & MS & df & MS \\
\hline Seedling type (ST) & 3 & $394.5^{\mathrm{NS}}$ & 3 & $2.7843^{* 2 \times k}$ & 3 & $0.07468^{\mathrm{NS}}$ & 3 & $5.149^{\mathrm{NS}}$ \\
\hline Error (a) & 8 & 267.5 & 8 & 0.1770 & 8 & 0.04899 & 8 & 0.601 \\
\hline Duration (D) & $2^{z}$ & & $3^{y}$ & & $3^{y}$ & & 4 & 27.894 \\
\hline Linear ()$\left._{1}\right)$ & 1 & $16563.8^{* * * *}$ & 1 & $19.1939^{* * *}$ & 1 & $6.63560^{* * * *}$ & 1 & $108.855^{* * *}$ \\
\hline Quadratic $(q)$ & 1 & $1132.1^{* * *}$ & 1 & $1.8970^{*}$ & 1 & $0.19403^{*}$ & 1 & $2.418^{* * *}$ \\
\hline Cubic & & & 1 & $0.7372^{\mathrm{NS}}$ & 1 & $0.00032^{\mathrm{Ns}}$ & 1 & $0.066^{\mathrm{NS}}$ \\
\hline Quartic & & & & & & & 1 & $0.249^{\mathrm{NS}}$ \\
\hline Temperature $(\mathrm{T})$ & 3 & & 3 & & 3 & & 3 & \\
\hline Linear & 1 & $3567.9^{* * *}$ & 1 & $7.1429^{* * * *}$ & 1 & $1.44504^{* * * *}$ & 1 & $17.507^{* * *}$ \\
\hline Quadratic & 1 & $4893.0^{* * * *}$ & 1 & $6.7308^{* * * *}$ & 1 & $2.67050^{* * *}$ & 1 & $26.520^{* * *}$ \\
\hline Cubic & 1 & $335.0^{\mathrm{NS}}$ & 1 & $0.1449^{\mathrm{NS}}$ & 1 & $0.03982^{\mathrm{Ns}}$ & 1 & $0.241^{\mathrm{NS}}$ \\
\hline $\mathrm{D} \times \mathrm{T}$ & 6 & & 9 & & 9 & & 12 & \\
\hline $\mathrm{D}_{1} \times \mathrm{T}_{1}$ & 1 & $805.7^{*}$ & 1 & $1.7316^{*}$ & 1 & $0.85683^{* * *}$ & 1 & $12.836^{* * *}$ \\
\hline $\mathrm{D}_{1} \times \mathrm{T}_{\mathrm{q}}$ & 1 & $4631.6^{* * *}$ & 1 & $2.1475^{* * *}$ & 1 & $1.55086^{* * *}$ & 1 & $13.988^{* * * *}$ \\
\hline $\mathrm{D}_{\mathrm{q}} \times \mathrm{T}_{1}^{\mathrm{q}}$ & 1 & $29.0^{\mathrm{NS}}$ & 1 & $0.0193^{\text {Ns }}$ & 1 & $0.01567^{\mathrm{Ns}}$ & 1 & $0.105^{\mathrm{NS}}$ \\
\hline $\mathrm{D}_{\mathrm{q}}^{\mathrm{q}} \times \mathrm{T}_{\mathrm{q}}$ & 1 & $807.5^{*}$ & 1 & $0.9245^{\mathrm{NS}}$ & 1 & $0.01787^{\mathrm{Ns}}$ & 1 & $0.178^{\mathrm{Ns}}$ \\
\hline Residual & 2 & $208.6^{\mathrm{NS}}$ & 5 & $0.2176^{\mathrm{NS}}$ & 5 & $0.02944^{\mathrm{NS}}$ & 8 & $0.299^{\mathrm{NS}}$ \\
\hline $\mathrm{ST} \times \mathrm{D}$ & 6 & & 9 & & 9 & $0.02610^{\mathrm{Ns}}$ & 12 & \\
\hline $\mathrm{ST} \times \mathrm{D}_{1}$ & 3 & $589.3^{*}$ & 3 & $0.4767^{\mathrm{Ns}}$ & & & 3 & $1.420^{* * *}$ \\
\hline $\mathrm{ST} \times \mathrm{D}_{\mathrm{q}}$ & 3 & $115.3^{\mathrm{NS}}$ & 3 & $0.5267^{\mathrm{Ns}}$ & & & 3 & $1.293^{\mathrm{NS}}$ \\
\hline Residual & & & 3 & $1.1363^{*}$ & & & 6 & $0.937^{\mathrm{NS}}$ \\
\hline $\mathrm{ST} \times \mathrm{T}$ & 9 & & 9 & $0.1592^{\mathrm{NS}}$ & 9 & $0.02210^{\mathrm{NS}}$ & 9 & $0.392^{\mathrm{NS}}$ \\
\hline $\mathrm{ST} \times \mathrm{T}_{1}$ & 3 & $106.0^{\mathrm{NS}}$ & & & & & & \\
\hline $\mathrm{ST} \times \mathrm{T}_{\mathrm{q}}$ & 3 & $371.0^{\mathrm{NS}}$ & & & & & & \\
\hline $\mathrm{ST} \times \mathrm{T}^{\mathrm{q}}$ & 3 & $600.4^{*}$ & & & & & & \\
\hline $\mathrm{ST} \times \mathrm{D} \times \mathrm{T}^{\mathrm{c}}$ & 18 & $159.0^{\mathrm{NS}}$ & 27 & $0.4018^{\mathrm{NS}}$ & 27 & $0.03179^{\mathrm{NS}}$ & 36 & $0.407^{\mathrm{Ns}}$ \\
\hline Error (b) & 88 & 159.0 & 120 & 0.2900 & 120 & 0.03144 & 152 & 0.286 \\
\hline Total & 143 & & 191 & & 191 & & 239 & \\
\hline
\end{tabular}

This ANOVA did not include the 20- and 30-day durations.

${ }^{y}$ These ANOVA did not include the 20-day duration.

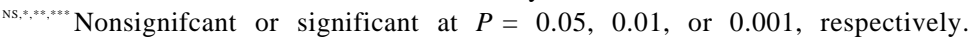

\section{Results and Discussion}

All main effects and many interactions were significant (Table 1). Logistics required that temperature treatments be provided simultaneously in the same growth chamber (only four growth chambers). We understand that this underestimated the error terms for the true variability of the systems. Generally, the probabilities for the F tests were extremely low, indicating with little doubt that these $\mathrm{F}$ tests were significant (Table 1).

Interactions between duration and temperature indicated that terminal shoot growth, lateral budbreak, shoot growth, and leaf growth all increased with longer chilling times at 2 to 10C (Fig. 2). No significant budbreak or growth occurred when seedlings were treated at $14 \mathrm{C}$. Very little terminal shoot growth occurred until the seedlings were treated for at least 50 days at 2 to $7 \mathrm{C}$. Terminal shoot growth had a high temperature optimum (7 or 10C) after chilling for 60 days. However, this result may be evidence of heat unit accumulation after the chilling requirement was completed. Lateral budbreak increased significantly between 30 and 40 days of chilling. There were no differences in lateral budbreak between
2, 7, and 10C. Leaf growth increased continuously with longer treatment durations. Leaf growth was significantly greater after chilling at $7 \mathrm{C}$ for 50 days, but there were no differences between 2,7 , and 10C at other durations. Shoot growth increased continuously with a quadratic response to temperature after 30 days of chilling, with an optimum at 7C.

Significant interactions occurred between seedling type and treatment duration for terminal shoot length, lateral budbreak, and leaf dry weight (Fig.3). Most of these differences can be explained by the differences between the seedling types before treatment. However, the most highly dwarfed seedlings (type 1) produced the most terminal shoot growth after subsequent chilling. This result suggested that PD trees may have the ability to store significant reserves, possibly partitioning more to the roots for later growth (not investigated). Lateral budbreak (per centimeter) was also highest for the smallest seedlings (type 1). These seedlings were severely dwarfed and had short internodes and more potential buds to break per centimeter. Still, root generated hormone levels may be higher in severely dwarfed seedlings (not investigated). Chilling enhancement of lateral budbreak was completed with only 40 

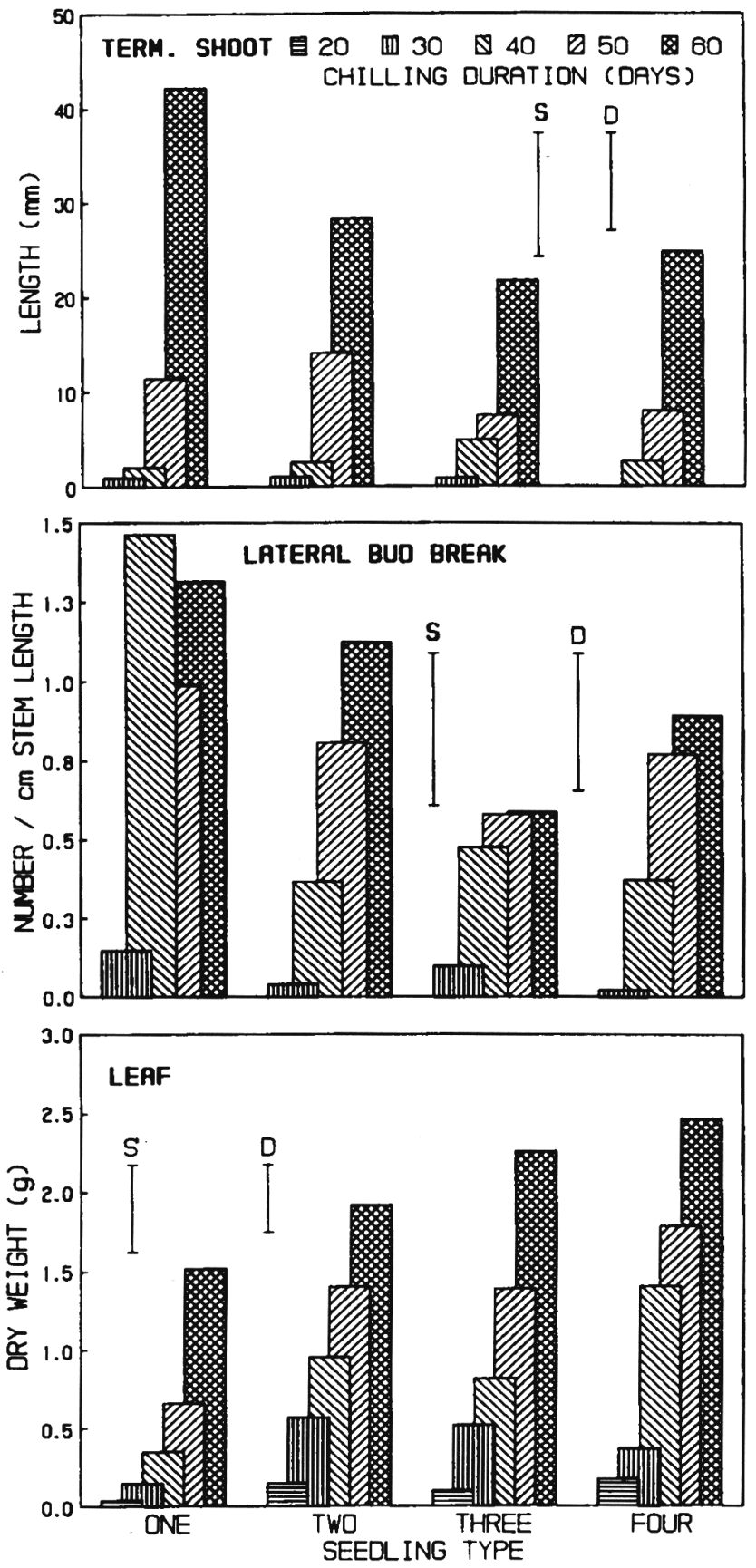

Fig. 3. Interaction between peach seedling type and treatment duration for terminal shoot length, lateral budbreak, and leaf dry weight of peach seedlings ('Johnson Elberta'). Values were averaged over four temperatures (2 to 14C). S represents the lsd 0.05 bar for comparison among seedling types when the duration is fixed. D represents the lsd 0.05 bar for comparison among durations when the seedling type is fixed. Trend analysis is provided in Table 1.

days stratification for seedlings with lateral stems (types 1 and 3). Seedlings with no lateral shoots (types 2 and 4) showed increasing budbreak with longer chilling. Leaf dry weights indicated that the larger seedlings (more original stem length) developed more leaves. This effect was enhanced after longer chilling treatments.

The only significant interaction between chilling temperature and seedling type was for terminal shoot growth (Fig. 4). The two larger seedling types (types 3 and 4), had similar terminal shoot growth when treated between 2 to $10 \mathrm{C}$. The smallest seedlings (type 1) had the most terminal shoot growth when treated at 7C.

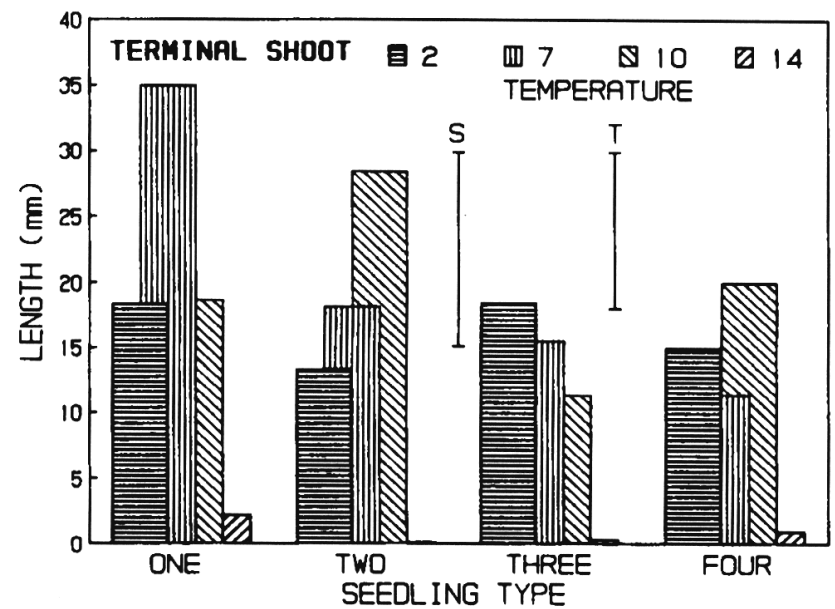

Fig. 4. Interaction between peach seedling type and treatment temperature for terminal shoot length of peach seedlings ('Johnson Elberta'). Values were averaged over three durations (40 to 60 days). S represents the lsd 0.05 bar for comparison among seedling types when the temperature is fixed. T represents the lsd $=0.05$ bar for comparison among temperatures when the seedling type is fixed. Trend analysis is provided in Table 1 .

Table 2. Correlation coefficients between terminal shoot length, lateral budbreak, shoot dry weight, and leaf dry weight of seedlings ('Johnson Elberta') after various chilling treatments (20 to 60 days at 2 to $14 \mathrm{C}$ ). Seedling types were separated according to size of the primary stem and, if present, the size of lateral stems. Type 1 was the smallest and had short laterals, type 2 was intermediate with no laterals, type 3 was intermediate with large laterals, and type 4 was large with no laterals (near normal).

\begin{tabular}{|c|c|c|c|}
\hline & \multicolumn{3}{|c|}{ Correlation coefficients $(r)$} \\
\hline & \multicolumn{2}{|c|}{ Forced 17 days } & $\begin{array}{l}\text { Grown } \\
64 \text { days }\end{array}$ \\
\hline Seedling type & $\begin{array}{c}\text { Terminal } \\
\text { shoot } \\
\text { length }\end{array}$ & $\begin{array}{c}\text { Lateral } \\
\text { budbreak }\end{array}$ & $\begin{array}{l}\text { Shoot } \\
\text { dry wt }\end{array}$ \\
\hline \multicolumn{4}{|c|}{ Leaf dry $w t$} \\
\hline Average & $0.57^{* * *}$ & $0.03^{\mathrm{NS}}$ & $\underline{0.88}^{* * *}$ \\
\hline 1 & $\underline{0.88}^{* * *}$ & $-0.04^{\mathrm{NS}}$ & $0.99^{* * * *}$ \\
\hline 2 & $0.81^{* * *}$ & $0.67^{*}$ & $\underline{0.97}^{* * *}$ \\
\hline 3 & $0.60^{* *}$ & $0.38^{\mathrm{NS}}$ & $\underline{0.91}^{* * *}$ \\
\hline 4 & $0.65^{* * *}$ & $0.60^{* * *}$ & $\underline{0.85}^{* * *}$ \\
\hline \multicolumn{4}{|c|}{ Shoot dry wt } \\
\hline Average & $0.66^{* * *}$ & $0.23^{*}$ & \\
\hline 1 & $\underline{0.88}^{* * *}$ & $0.02^{\mathrm{NS}}$ & \\
\hline 2 & $\overline{0.78^{* * *}}$ & $0.79^{* * * *}$ & \\
\hline 3 & $0.67^{* * *}$ & $0.60^{\mathrm{NS}}$ & \\
\hline 4 & $0.42^{\mathrm{NS}}$ & $0.47^{*}$ & \\
\hline \multicolumn{4}{|c|}{ Lateral budbreak } \\
\hline Average & $0.26^{*}$ & & \\
\hline 1 & $0.07^{\mathrm{Ns}}$ & & \\
\hline 2 & $0.50^{*}$ & & \\
\hline 3 & $0.01^{\mathrm{Ns}}$ & & \\
\hline 4 & $0.28^{\mathrm{Ns}}$ & & \\
\hline
\end{tabular}

Correlations for underlined values explained $>70 \%$ of the variability. ${ }_{\text {NS, }, *+*, * * *}$ Nonsignificant or significant at $P=0.05,0.01$, or 0.001 , respectively.

Yet, seedling type 2 (short terminal and no lateral shoots) had the most terminal shoot growth when they were treated at 10C. The importance of these differences has not been determined. 
Correlations between terminal shoot growth and budbreak (after 17 days forcing) and total leaf and shoot seedling growth (after 64 days of growth) were low (Table 2). Different seedling types may have prevented good correlations due to population differences, so the same correlations were calculated for each seedling type. Correlations between terminal shoot growth and shoot or leaf dry weight were relatively high for the smallest seedling type (type 1), but they were lower for the larger types (Table 2). We had hoped that terminal shoot growth or lateral budbreak could have been used as a predictor of subsequent seedling growth, but this was not possible with a single bud reading at 17 days of forcing.

Terminal shoot growth and lateral budbreak after 17 days forcing and total leaf and shoot growth after 64 days, all increased significantly after chilling treatments longer than 40 days. The

\section{Literature Cited}

Chao, L. and D.R. Walker. 1966. Effects of temperature, chemicals, and seed coat on apricot and peach seed germination and growth. Proc. Amer. Soc. Hort. Sci. 88:232-238.

Davidson, O.W. 1934. Growing trees from 'non-viable' peach seeds. Proc. Amer. Soc. Hort. Sci. 32:308-312.

Flemion, F. 1934. Dwarf seedlings from non-after-ripened embryos of peach, apple, and hawthorn. Contrib. Boyce Thompson Inst. 6:205209.

Flemion, F. 1959. Affect of temperature, light and gibberellic acid on stem elongation and leaf development in physiologically dwarfed seedlings of peach and rhodotypos. Contrib. Boyce Thompson Inst. 20:57-70.

Flemion, F. and J. Beardow. 1963. Histological studies of physiologically dwarfed peach seedlings. I. Structure of anomalous leaves. Contrib. Boyce Thompson Inst. 22:117-131.

Frisby, J.W. and S.D. Seeley. 1993a. Chilling of endodormant peach propagules: I. Seed germination and emergence. J. Amer. Soc. Hort. Sci. 118:248-252. chilling requirement of the 'Elberta' peach flower buds has been reported to be 37 days at 6C [880 chill units (Richardson et al., 1974)]. Many initial changes occurred during the first 40 days, but longer treatments promoted more vegetative budbreak and growth. Our results indicate that chilling is a continuous process for vegetative growth of peach seedlings (Frisby and Seeley, 1993c).

These seedlings were obtained from an open pollinated peach cultivar; some seedling types could have been due to genetic differences in the seedling population. This possibility could explain some of the significant interactions between the chilling treatments and the seedling types. Yet, shoot growth was similar for all seedling types (Table 1). Our results show that shoot growth is the best indicator of the chilling response or endodormancy release of peach seedlings ranging from PD to near normal.

Frisby, J.W. and S.D. Seeley. 1993b. Chilling of endodormant peach propagules: II. Initial seedling growth. J. Amer. Soc. Hort. Sci. 118:253257.

Frisby, J.W. and S.D. Seeley. 1993c. Chilling of endodormant peach propagules: V. Comparisons between seeds, seedlings, and cuttings. J. Amer. Soc. Hort. Sci. 118:269-273.

Richardson, E.A., S.D. Seeley; and D.R. Walker. 1974. A model for estimating the completion of rest for 'Redhaven' and 'Elberta' peach trees. HortScience 9:331-332.

Tukey, H.B. and R.F. Carlson. 1945. Morphological changes in peach seedlings following after-ripening treatments of the seeds. Bot. Gaz. 106:431-440.

Wang, D. and J. Beardow. 1968. Thermo-, photo-effect on rosaceous seeds during germination as expressed in subsequent seedling development. Contrib. Boyce Thompson Inst. 24:17-23.

Zigas, R.P. and B.G. Coombe. 1977. Seedling development in peach, Prunus persica (L.) Batsch. I Effects of testas and temperature. Austral. J. Plant Physiol. 4:349-358. 